\title{
UC groundwater research: A survey
}

\author{
As California implements the Sustainable Groundwater Management Act (SGMA), UC research \\ is building knowledge and supporting innovation in groundwater recharge, groundwater \\ accounting, groundwater quality, groundwater governance and more. Here's a sample of work \\ from across the UC system.
}

Relationships among potential water budget components and the water systems that comprise the hydrologic cycle. Source: California Department of Water Resources, Water Budget Best Management Practice, December 2016.

\section{Whole-watershed accounting}

Whole-watershed accounting assesses all surface and groundwater flows and storage over a large area. The idea is to account for all the major sources of water at once, rather than focusing on only a portion of them, such as what's stored in surface water reservoirs. This work can reveal how joint management of surface and groundwater flows and storage could increase the overall amount of water available on decadal time scales.

Graham Fogg, professor of hydrogeology at UC Davis, leads a group conducting this type of analysis on a region that spans the American River and Cosumnes River watersheds - a project being conducted through the UC Water Security and Sustainability Research Initiative. Using data and models on historical conditions, combined with information about the available storage space in the region's aquifers and the availability of geologically suitable groundwater recharge sites, the researchers are finding that optimizing the use of all available storage space - above as well as below ground - could have increased net water storage on the order of hundreds of thousands of acre-feet per year, on average.

"Imagine all of your money is in two bank accounts, but you only manage one of them. With water, we've been managing the surface water bank account, but not the groundwater account," Fogg said. "They need to be managed together. Furthermore, we also need to better track and manage the snow account."

\section{Water availability for recharge}

On a larger scale, Helen Dahlke, professor of hydrology at UC Davis, and Thomas Harter, professor of water management and policy and UC Cooperative Extension (UCCE) specialist at UC Davis and director of the UCCE groundwater program (groundwater.ucdavis.edu), are modeling the impact

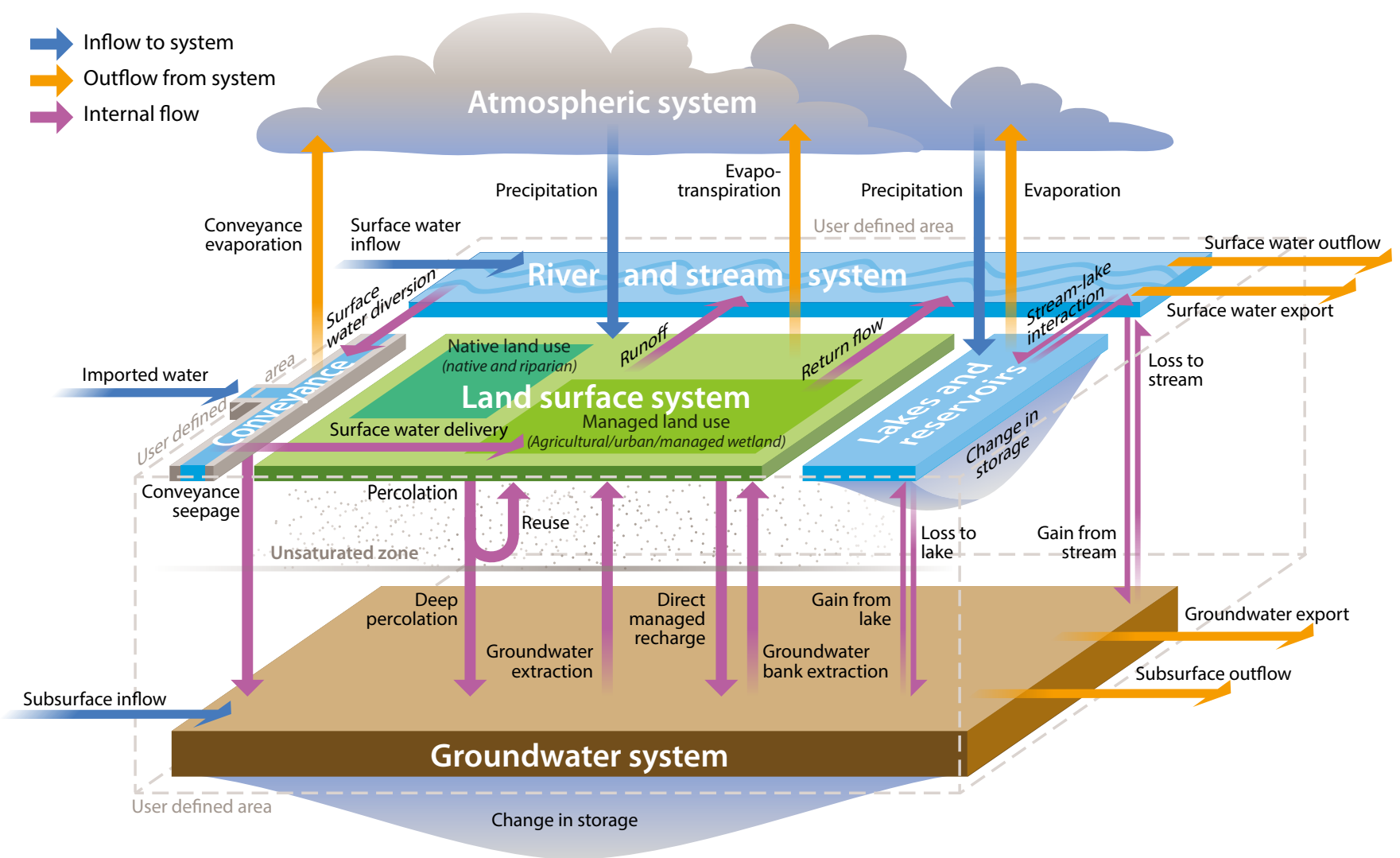


of large-scale groundwater recharge across the entire Central Valley. Using historical flow records, they assess the magnitude, frequency and duration of high-magnitude streamflows (e.g., flood flows) in watersheds around the valley (Kocis and Dahlke 2017), and simulate the impact that recharge of these "excess" streamflows could have on Central Valley groundwater resources using the C2VSIM groundwater-surface water model.

"It wouldn't be the panacea that some think," said Harter. "But we're finding that if we do this consistently, we'll gain some water storage, and - in some cases - we'll also gain some downstream summer and fall streamflow due to a higher water table near some streams."

\section{Precision data on snowmelt}

At UC Merced, Mohammad Safeeq, research scientist at the Sierra Nevada Research Institute, Martha Conklin, professor of engineering, and Roger Bales, professor of engineering, are leading several projects across the Sierra Nevada headwaters to gather and utilize higher-resolution in-situ information on the magnitude and timing of snowmelt (Bales et al. 2018; Zhang et al. 2017a; Zhang et al. 2017b)

These projects, a collaboration with Steven Glaser, systems engineering professor at UC Berkeley, use distributed wireless sensor networks technology, in which hundreds of sensors are placed strategically in clusters to develop a picture of snow water content in a watershed.

The use of many sensors enables the capture of data reflecting the wide variability in snow conditions in a watershed - snow cover along an elevation gradient, beneath tree canopies as well as in open areas, on hillsides with a range of slopes and aspects, and so on. These sensors also gather information on other key hydrologic variables such as soil moisture and air and soil temperatures. The approach is a significant improvement over traditional systems that are limited to a handful of easily accessible measurement stations scattered throughout a basin.

The data can then be combined with numerical models to estimate, in near-real-time, how much water is in the Sierras, and when water from snowmelt will arrive in streams and reservoirs. That information, in turn, can inform the planning and operation of groundwater recharge projects as well as surface water reservoirs. This unique dataset is also helping to inform forest management - researchers are working towards evaluating the impacts of different forest management prescriptions on water balance and forest health and resilience.

The distributed snow sensor networks along with numerical modeling have been or are being deployed in portions of several Sierra watersheds, in the Feather, American, Stanislaus, Merced and Kings river basins.

\section{Spatial data on well vulnerability}

At UC Santa Barbara (UCSB), Debra Perrone, professor of environmental studies, is leading a study to map the locations of the millions of groundwater wells in the United States, as well as their vulnerability to falling groundwater levels and water quality problems.

In earlier work, Perrone and collaborator Scott Jasechko, professor in the Bren School of Environmental Science and Management at UCSB, used well-construction records as well as data on groundwater levels to map the locations of likely dry wells across California and other western states (Perrone and Jasechko 2017). Their current project expands the geographic scope to the entire continental United States, and adds additional data on water quality impairment. For example, Perrone and Jasechko have also used the groundwater well data to evaluate the proximity of hydraulic fracturing operations to domestic groundwater wells to identify hotspots that may be used to target further water-quality monitoring (Jasechko and Perrone 2017).

\section{Large-scale groundwater recharge and agricultural systems}

Dahlke and Sam Sandoval, professor and UCCE specialist in water management at UC Davis, recently launched a 3-year project with the U.S. Department of Agriculture Economic Research Service to assess the economic costs and benefits of different managed aquifer recharge methods (e.g., on-farm recharge, infiltration basins, recharge of recycled or treated wastewater, and in lieu recharge) in the Central Valley to determine which economic incentives are needed to increase groundwater recharge efforts statewide.

To do this, they will integrate existing large-scale groundwater-surface water hydrologic models with economic models - developed by the Economic Research Service and by Ariel Dinar, professor of environmental economics and policy at UC Riverside (UCR) - that incorporate crop production practices, land and water policies, land values, production and capital costs and other factors.

The project will focus on California's Central Valley as well as the lower Mississippi River region - another agricultural region with high groundwater use - and will include collaborations with researchers at UCR and the University of Arkansas.

\section{Groundwater-surface water interactions}

SGMA requires groundwater sustainability agencies (GSAs) to manage groundwater such that significant and unreasonable impacts on beneficial uses of interconnected surface waters are avoided. 
Groundwater-surface water interactions. Source: California Department of Water Resources, Water Budget Best Management Practice, December 2016.
Harter leads several projects to model groundwatersurface water interactions at the local level. An article in this issue (page 84) models these relationships in the Scott Valley, an agricultural region in Siskiyou County where groundwater levels have a strong influence on streamflows and salmon habitat in the Scott River.

The management of groundwater-surface water interactions raises legal and policy questions in addition to scientific ones. In an upcoming paper from the Wheeler Water Institute at UC Berkeley and the UC Water initiative, Harter, Wheeler Water Institute Director Michael Kiparsky and collaborators report on discussions on these topics at a series of expert workshops hosted in 2017 that brought together thought leaders in hydrogeology, law and policy (Cantor, Owen et al. 2018).

Topics covered include: examples of conflicts between groundwater and surface water users and how conflicts have been resolved; how SGMA alters or should alter legal relationships between groundwater and surface water users; the tools needed to identify and address potential conflicts between groundwater and surface water uses; and the interactions between SGMA and other laws governing water use and environmental protection.

The report synthesizes content from the workshops, legal analysis, and technical and legal literature review,
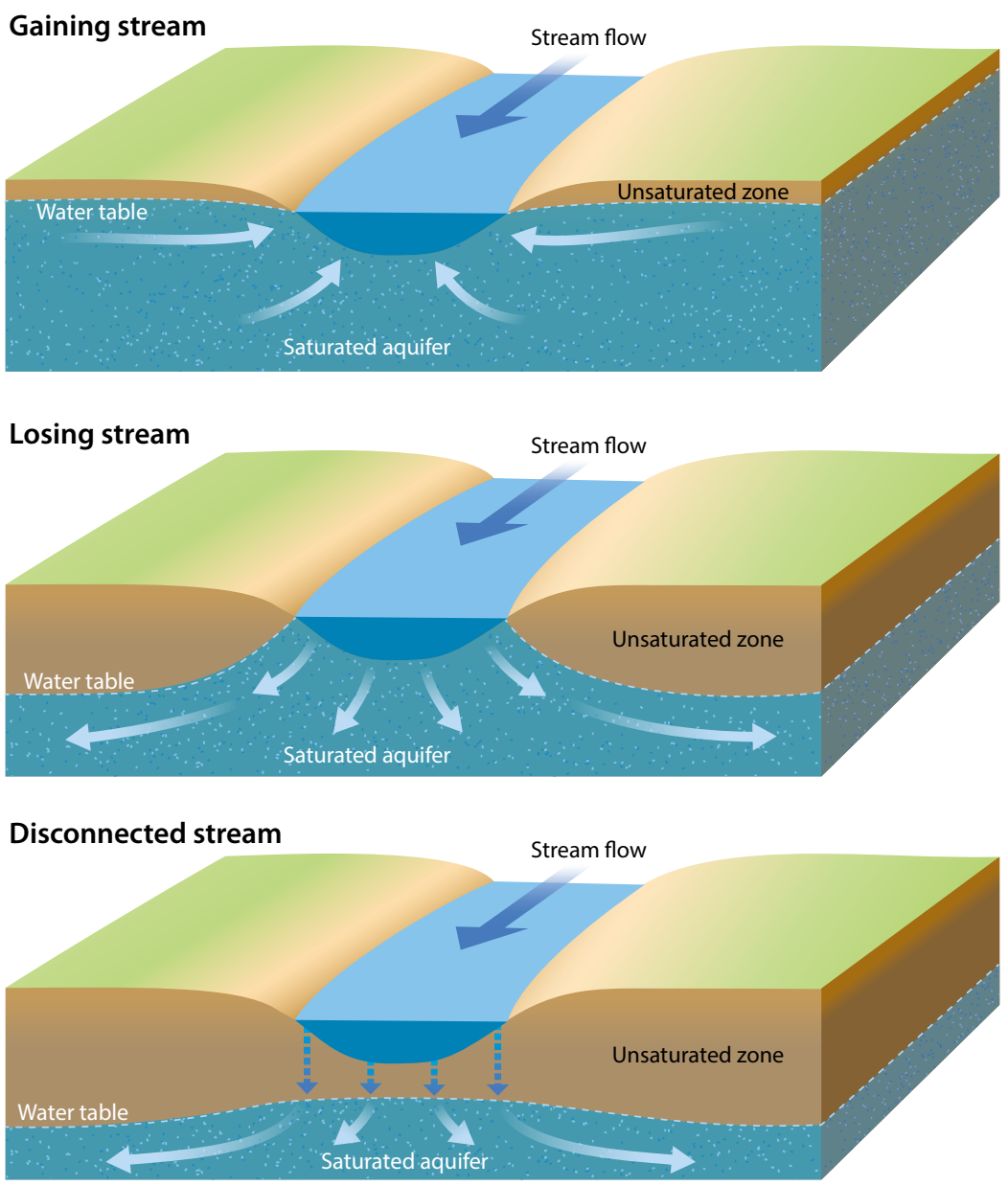

and identifies key themes, with the objective of providing guidance and practical advice for practitioners, including groundwater managers and state agency staff.

\section{Groundwater quality and salinity}

SGMA and other state regulations also require that groundwater management not degrade water quality (see Harter 2015 for an overview of the multiple regulatory programs concerning groundwater quality).

In agricultural regions, nitrate contamination of drinking-water aquifers and long-term salinization of groundwater for all uses are generally the major concerns.

Much of Harter's work focuses on nitrate. He and Jay Lund, professor of civil and environmental engineering at UC Davis, led the development of a major statewide assessment of nitrate contamination of drinking water wells in agricultural regions. The report was released in 2012, with a significant update in 2017 (groundwaternitrate.ucdavis.edu/).

Harter's work investigates a variety of aspects of nitrate in groundwater - major nitrate sources, subsurface transport and transformation of nitrate, and interactions of nitrate flows with wells, surface water streams and aquifer recharge projects.

A broad lesson of this research, Harter said, is the need for an integrated collection of changes in farming and water management practices: More-efficient application of water and fertilizer during the growing season, combined with increased application of clean water in winter. That combination of practices would reduce in absolute terms the amount of nitrate applied to farmlands, and replace flows of nitrate-contaminated water into aquifers with flows of cleaner water that may help to dilute existing contamination and refill depleted groundwater basins.

Salinization is a separate but related groundwater quality issue, particularly in the Tulare Basin - roughly the southern third of the Central Valley which depends heavily on groundwater for irrigation.

Irrigation water - whether sourced from a river, from the Delta via canal, or from a groundwater well - contains salts. As groundwater is extracted and used to irrigate crops, water leaves the system through evapotranspiration, but salts are left behind. These salts percolate steadily downward, eventually reaching the aquifers that supply agricultural wells.

Because of the intensity of groundwater use in the Tulare Basin, the area's groundwater system has effectively become a closed hydrological basin, akin to Mono Lake or the Salton Sea. In the past, groundwater in the basin had outlets, through connections with surface water and horizontal flows beneath the surface, and hence the groundwater stayed fresh. But now, due to groundwater depletion, the dominant way that groundwater leaves the basin is via pumping and evapotranspiration on farmland. As a result, the groundwater in the basin can only become more saline. 
This is also true of other parts of the Central Valley and the world, where even moderate groundwater development, together with irrigation, has converted groundwater basins from being open, with water and salts exiting via natural pathways, to closed basins in which the salts accumulate in the groundwater.

Fogg's research group is modeling the salinization rate of groundwater in the Tulare Basin. If current practices continue, in the foreseeable future - within about 50 years for shallow aquifers and 100 years for deeper aquifers - much of the groundwater will become too saline to irrigate most crops. The salinization could be slowed by reducing groundwater extraction or increasing recharge with low-salinity water, Fogg said. Fogg's group is creating groundwater quality management models for determining how land and water management could be changed in order to put groundwater quality on a more sustainable path.

\section{Water supply, land use and rural communities}

UC Davis' Dahlke is leading a $\$ 1.6 \mathrm{M}$ project funded by the National Science Foundation (NSF) to analyze the relationships between surface water and groundwater supply, agricultural land use and the economic wellbeing of rural communities.

The team will incorporate survey data with economics and hydrology expertise to develop models to help guide decision-making around water management and land use in the state.

The project is one of nine funded nationwide under the NSF's Dynamics of Coupled Natural and Human Systems program. While Dahlke's team will focus on the Tulare Basin, the work is expected to provide insights applicable to other regions of the United States facing similar issues involving economic and water security.

The project also seeks to help local disadvantaged communities participate in the governance of water resources, including through the creation of "water schools" and engaging K-12 students in science and policy issues. The Visalia-based Community Water Center (see article page 20) is a co-principal investigator on the project.

\section{Data on water use and water rights}

UC researchers are also working to address the broad problem of a lack of centralized, well-indexed, accessible data relevant to water management in California. Legislation passed in 2016 - AB 1755, the Open and Transparent Water Data Act - charges state agencies to make such data available for a range of water management challenges including SGMA implementation.

It's a major information challenge, covering hundreds of data sets from state, federal, university and private sources that cover water as well as ecology, agriculture, infrastructure, geology, soils, climate and socioeconomics.

UC Berkeley's Kiparsky, UC Merced's Bales and a multi-institutional group of collaborators are working with the California Department of Water Resources to support the development of information systems that can effectively support water management.

The effort approaches the water data challenge from a software design perspective - starting by working to understand how people use (or would like to use) the data to make decisions or inform management, and then building systems to serve those needs (Kiparsky and Bales 2017). With their collaborators, they convened a series of three stakeholder workshops to develop the concept of use cases for water data, along with a method for generating them. They generated a collection of 20 use cases that illustrate the data needs for a range of water-related decisions, such as planning a groundwater recharge project or developing a groundwater basin water budget (available at http://law. berkeley.edu/datafordecisions).

Based on these data, the group published a policy paper with recommendations in January (Cantor, Kiparsky et al. 2018), which has helped directly inform DWR's efforts on AB 1755 implementation.

Along with water attorney Richard Roos-Collins, Kiparsky is also leading a pilot project to tackle another major data gap in California water management - water rights.

Surface water rights documents in California currently are stored as millions of pieces of paper at the offices of the State Water Resources Control Board in Sacramento, in county courthouses around the state, and in other repositories. Digitizing and making these documents accessible could increase transparency, and remove a barrier to management tools such as water markets and as-yet-unimagined innovations for water management where groundwater and surface water intersect under SGMA.

Last year, the Kiparsky and Roos-Collins team won the California Water Policy Challenge competition held by the water technology accelerator Imagine $\mathrm{H} 2 \mathrm{O}$, for a proposal to begin building a water rights database for California. They are engaging state agencies and stakeholders in a process to develop robust standards for such a database, along with a pilot project in the Mono Basin, in partnership with the Los Angeles Department of Water and Power.

\section{Managed aquifer recharge on farmland}

Managed aquifer recharge is the deliberate recharge of groundwater with surface water through infiltration basins or injection wells. Using wintertime stream diversions as a water source and orchards and fields as infiltration basins is a promising approach to increase overall recharge in many of California's agricultural regions. A number of UC research groups are working 
and recharging runoff is likely to become increasingly important.

UCSC doctoral candidate Sarah Beganskas has been modeling the Pajaro River watershed to identify good sites for distributed stormwater collection projects, based on information including topography, vegetation cover, soil type, aquifer locations and groundwater levels.

Collecting and infiltrating just a few percent of a watershed's total runoff during heavy rainfall events can increase groundwater recharge substantially. A pilot project on a 172-acre property in the Pajaro Valley infiltrated more than 100 acre-feet annually even in the dry 2015-2016 winter (Beganskas and Fisher 2017)

\section{Net metering for groundwater}

A significant hurdle to the expansion of distributed stormwater collection projects - and for groundwater recharge project on farmland in general - is the need to provide an incentive for individual landowners to put projects on their land. Recharge projects have initial and ongoing expenses, and involve some loss of land use and local impact - for instance by adding fine sediment, which can impair soil drainage. In addition, recharged water flows into a general subsurface pool, rather than all being available for withdrawal by the landowner who went through the trouble to recharge it (that is, it's not like a bank, where all deposits are available for withdrawal).

Recharge net metering is an institutional innovation designed to provide a clear financial incentive to develop individual recharge projects. Fisher and colleagues at UCSC, along with the Resource Conservation District-Santa Cruz County, are leading a 5-year pilot of the concept in the Pajaro Valley, in collaboration with the Pajaro Valley Water Management Agency (Kiparsky et al. 2018).

The concept is modeled on net metering in electricity, which is used widely to incentivize home-scale rooftop solar panels: When panels produce more electricity than a home is using, the excess flows into the power grid, and the homeowner receives a credit on her electricity bill to offset power drawn from the grid at other times.

In the Pajaro Valley, agricultural water users currently pay a fee of $\$ 217$ or more per acre-foot of water pumped (most agricultural pumpers around the state don't pay a water extraction fee now, but it's likely that it will become more common as groundwater sustainability plans (GSPs) are implemented under SGMA). Under the net metering pilot project, the owner of a groundwater recharge project receives a credit against that fee based on the amount of water infiltrated as a result of the project. The rebate is set at half of the value of the additional water infiltrated, to account for uncertainties associated with recharge and the fate of infiltrated water.
The pilot program is targeting roughly 1,000 acrefeet per year of new groundwater recharge, through perhaps 10 projects. It is designed to clarify various issues associated with administering a net metering system, such as financial sustainability, the economics of small recharge projects, and accuracy in water accounting.

Fisher is collaborating with Kiparsky and Michael Hanemann, professor of agriculture and resource economics at UC Berkeley, who are leading a related project, funded by the U.S. Department of Agriculture and the UC Office of the President, to examine the institutional and economic elements of the recharge net metering concept to evaluate prospects for scaling and broad adoption.

\section{Geophysical imaging}

Fogg's group has for a number of years been using data from well-drilling logs to map locations where sandy soils extend from the surface to the underlying aquifer - such sites indicate a prime location for groundwater recharge. The information is complementary to the SAGBI map (O'Geen et al. 2015), which is based on several sources of data about near-surface soil conditions. It's limited, however, by the availability of well-drilling logs. Advanced geophysical remote sensing tools now make it possible to generate a more complete map of these surface-aquifer connections, but they are costly. A helicopter-based airborne electromagnetic method, Fogg said, could be deployed to map the Central Valley, as shown in a recent demonstration project in the $\mathrm{Tu}$ lare Lake Basin (Knight et al. in press).

Separately, LBNL's Nico and team are evaluating the use of satellite-based sensing of ground elevation as a way to detect changes in groundwater storage. The technology, known as interferometric synthetic aperture radar, or InSAR, can detect millimeter-scale changes in soil elevation. Because ground elevation rises or falls slightly in response to aquifer recharge or depletion, the technique may prove useful in quickly assessing groundwater storage over large areas.

\section{Groundwater governance}

Researchers at the UC Davis Center for Environmental Policy and Behavior are using social science approaches to study a range of issues regarding SGMA processes and implementation. The research team includes Professor Mark Lubell, and graduate students Linda Esteli Mendez-Barrientos, Jessica Rudnick, Kristin Dobbin, Amanda Fencl, Sean Maxson, and Mackenzie Johnson.

Their research has focused on four main questions: What is the structure and diversity of institutional arrangements for groundwater sustainability agencies and plans? How do different policy actors participate and cooperate in SGMA governance processes? How do political leaders and facilitators influence the evolution of governance institutions within and 
across groundwater basins? How does the process of institutional change reflect differential access to water resources and power, and the consequences for procedural and distributional equity? All of these questions reflect core theoretical issues in social science, but have direct practical implications for SGMA implementation.

While many of the research projects are in the early stages, some intriguing initial findings have emerged. Qualitative research on GSA development suggests that facilitation services, information and knowledge sharing, small agency sizes, common 'adversarial' conditions and participation in other water policy processes have contributed to the emergence of collaborative GSAs - those that include at least nominal representation from stakeholders beyond counties and water districts such as private pumpers and disadvantaged communities. However, even within these GSAs, power asymmetries among participants are shaping institutional outcomes (Méndez-Barrientos, in review). For example, initial findings indicate limited representation of disadvantaged communities and involvement in the SGMA process. About $10 \%$ of groundwater-dependent disadvantaged communities analyzed thus far are represented on their respective GSAs. Likewise, Rudnick et al. (2016) created a diversity index for agriculture that predicts which basins will face steeper challenges in equitably addressing the needs of their diverse agricultural stakeholders.

Doctoral student Linda Esteli Méndez-Barrientos noted that the sort of decentralized water resources management framework created by SGMA has been enacted in a number of other countries, such as South Africa. That body of experience creates a rich opportunity for comparative study, and helps to inform the questions that the group is asking about the institutions created under SGMA. "Around the world, there's a lot of idealistic legislation, but there's a huge gap between what's envisioned and what's implemented. My job is to understand that gap," said Méndez-Barrientos.

In February, Lubell's group along with other UC Davis researchers working on SGMA convened a conference at UC Davis that brought together SGMA researchers from across the country with SGMA practitioners and government agencies. The goal of the conference was to synthesize current knowledge about SGMA governance challenges and establish a policyengaged research agenda that connects governance theory with SGMA practice. A synthesis of conference proceedings will be available in spring 2018.

\section{Lessons on groundwater permitting from around the West}

Many GSPs developed under SGMA are likely to include the implementation of a permitting system for groundwater extraction.

To support that process, UCSB's Perrone is leading a project to build a publicly accessible database of permitting systems used by groundwater management agencies from the western 17 states. The database will include details on metering, monitoring, reporting and other requirements (e.g., Nelson and Perrone 2016).

The information will be published this spring via an interactive online dashboard hosted by Stanford University's Water in the West program, where Perrone was a postdoctoral researcher prior to joining the UCSB faculty in 2017.

Next steps in the project include an analysis of the data to identify successful approaches to groundwater management that may be applicable to GSAs as the agencies develop their GSPs. As part of this work, Perrone and colleague Rebecca Nelson will survey groundwater managers to identify which aspects of permitting authority groundwater managers exercise most frequently and find most useful.

\section{Supporting GSP development}

Under SGMA, a key piece in generating a local GSP is the development of a groundwater basin diagnosis, called a water budget, that incorporates data on current aquifer conditions, sources of recharge, extraction via wells, and water flows within the aquifer. With this information, a basin's sustainable yield can be calculated - and from that, the net rate of extraction that the basin can support sustainably.

The work of UC researchers is informing and supporting this process in a number of basins. In Mendocino County, for instance, a team of UC ANR academics and graduate students led by Sandoval conducted a water budget project in the Ukiah Valley, which is classified as a medium-priority subbasin under SGMA. The work determined the current status of the basin and informed this result to stakeholders during the formation of the GSA in the area, and is informing the development of the basin's GSP.

Important findings include that the basin is not in overdraft, and that the Russian River gains water from the aquifer and tributaries from November to June and loses water into the aquifer from July to October (Marquez et al. 2017).

\section{The economics of sustainable groundwater management}

SGMA calls for sustainable management, but leaves much leeway to local stakeholders - through the groundwater sustainability agencies - to define what sustainability means in their basin.

Economic modeling can provide insights about what constitutes long-term sustainability, and the relationships among the many variables that influence groundwater management. Kurt Schwabe, professor of environmental economics and policy at UCR, oversees multiple projects in this area. 
One, led by recent UCR Ph.D. graduate Brad Franklin (now at the Gulf of Maine Research Institute) with collaborators from UCR and the University of Minnesota, models the effects of perennial crop irrigation on future groundwater levels.

The recent extreme drought in California has led to significant changes in land and water use by the state's agricultural sector. Market pressures have encouraged a further shift from annual crops to lucrative perennial crops such as almonds, which had already exacerbated the high dependence of irrigation on groundwater pumping to meet the crop's high water requirements and protect investments in new perennial crops. Yet there has been no formal economic modeling of the potential effects of perennial crop irrigation on future groundwater levels.

The project develops an integrated economic model of groundwater use and perennial crop production in Kern County that captures both groundwater and perennial crop dynamics. The research identifies the degree to which shifting acreage into perennial crop production along with climate change influence both the costs of groundwater management and the difficulties in meeting particular groundwater sustainability goals. It also highlights the added vulnerability growers confront from such shifting cultivation under different climate change scenarios, and the implications on both the elasticity of demand for water and role of water markets.

Another project, led by Keith Knapp, professor of resource economics at UCR, and Franklin, extends the standard groundwater model typically used for economic optimization of groundwater management. Their model adds consideration of household consumption, investments in manufacturing capital, and budget constraints, and adjusts optimization criteria to ensure equity over time.

The result is a model that better reflects sustainable management and that leads to several qualitative conclusions about what that entails. First, declining resource stocks are not necessarily indicators of non-sustainability - and they may in fact be necessary for sustainability since they tend to drive investment. Second, unregulated usage is not the only - or even necessarily the main - cause of nonsustainability. Sustainability is driven more by how rents from groundwater are invested in other sectors (e.g., manufacturing or finance) rather than resource management.

\section{Considerations for groundwater markets}

SGMA authorizes GSAs to assign groundwater extraction allocations to pumpers and provide for trading of those allocations - thus creating the basis for the development of local groundwater markets.

Economic theory suggests that such markets could, under certain conditions, promote more efficient allocation of groundwater resources. But markets can also have negative effects, or externalities - for instance, if a groundwater trade between two parties harms a third party or the environment.

To help GSAs as they consider whether and how to implement a trading system, a report from the Wheeler Water Institute at the UC Berkeley School of Law (Green Nylen et al. 2017) presents a (long) list of considerations for the development of groundwater markets: from foundational aspects like how groundwater extraction will be measured; to market-specific issues such as interactions between groundwater extraction allocations and existing groundwater rights, and the various potential impacts of trades; to general considerations like monitoring, enforcement and public engagement.

\section{The role of cooperation and markets}

In order to leverage local knowledge and honor pumpers' unique circumstances, SGMA foresees groundwater users themselves crafting plans to meet its requirements. However, pumpers often disagree about how to allocate access to groundwater, especially when some stand to lose economically from restricting pumping. Such users fight institutional change, thereby creating obstacles to addressing overextraction. These obstacles increase the economic costs of negotiating agreement, termed "contracting costs." Regulators and SGMA stakeholders alike can benefit from better understanding how rules for accessing groundwater pay dividends, and how contracting costs block collective action.

To answer these questions, researchers from UC Santa Barbara are analyzing historical changes in groundwater access institutions in basins across California. Andrew Ayres, previously a Ph.D. candidate at UCSB and now an economist with Environmental Defense Fund, Kyle Meng, assistant professor at the Bren School of Environmental Science \& Management, and Andrew Plantinga, professor at the Bren School, are assessing the economic returns to addressing overextraction by clarifying the definition of rights to the resource. Defining groundwater rights entails setting a cap on the groundwater volume that can be pumped annually and allocating tradable permits among users. This process improves long-term resource availability and allows flexible reallocation of water use. In statistically comparing land parcels with well-defined and poorly defined rights to the Mojave groundwater aquifer, Ayres and colleagues find that more clearly defining property rights caused land values to increase by over $50 \%$, on average; this reflects an increase in the value of water rights held on each parcel. Aggregate gains exceeded $\$ 60$ million (Ayres et al., 2018 working paper).

Despite the promise of gains, many basins where more restrictive access rules are needed remain in critical overdraft. High contracting costs that obstruct 
collective action are one explanation. Ayres, Eric Edwards, assistant professor at North Carolina State University, and Gary Libecap, professor at UCSB's Bren School, are examining systematically how these costs vary across basins. The researchers statistically compare basins that have adopted effective institutions with otherwise similar basins where institutions are fragmented or nonexistent and document a critical role of contracting costs in explaining the inability to adopt management. These costs increase with basin size, the number of users, dispersion in water uses and valuations, and spatial variance in recharge within a basin (Ayres et al., in press).

How can pumpers and regulators facilitate agreement? Tradable pumping rights are advantageous in cases where allocating these rights to otherwise recalcitrant landowners is important for overcoming opposition. Additionally, different institutional rules entail different levels of costs, so stakeholders should remain open to approaches that economize on contracting costs by addressing relevant issues without defining pumping allocations or including all potential actors; for example, pumpers have historically adopted spatially restricted management rules to address local overdraft and written contracts to share imported water in order to avoid costly bargaining over cutbacks. CA

\section{References}

Ayres A, Edwards E, Libecap G. In press. How transaction costs obstruct collective action: Evidence from California's groundwater. J Environ Econ Manag. Ayres A, Meng K, Plantinga A. 2018. The economic value of secure water: Landowner returns to defining groundwater property rights. Working paper, available upon request.

Bales RC, Goulden ML, Hunsaker CT, et al. 2018. Mechanisms controlling the impact of multi-year drought on mountain hydrology. Sci Rep 8:690. https://doi.org/10.1038/s41598017-19007-0

Beganskas S, Fisher AT. 2017. Coupling distributed stormwater collection and managed aquifer recharge: Field application and implications. J Environ Manage 200:366-79. https://doi.org/10.1016/j.jenvman.2017.05.058

Cantor A, Kiparsky M, Kennedy $R$, et al. 2018. Data for water decision making: Informing the implementation of California's open and transparent water data act through research and engagement. Center for Law, Energy \& the Environment, UC Berkeley School of Law. https:// doi.org/10.15779/J28H01

Cantor A, Owen D, Harter T, et al. 2018. Navigating groundwater-surface water interactions under the Sustainable Groundwater Management Act. Center for Law, Energy \& the Environment, UC Berkeley School of Law. https://doi.org/10.15779/ J23P87
Green Nylen N, Kiparsky M, Acher K, et al. 2017. Trading sustainably: Critical considerations for local groundwater markets under the sustainable groundwater management act. Center for Law, Energy \& the Environment, UC Berkeley School of Law. law.berkeley.edu/tradingsustainably

Harter T. 2015. California's agricultural regions gear up to actively manage groundwater use and protection. Calif Agr 69:193-201. https://doi. org/10.3733/ca.E.v069n03p193

Jasechko S, Perrone D. 2017. Hydraulic fracturing near domestic groundwater wells. P Natl Acad Sci 114:13138-43. http://doi. org/10.1073/pnas.1701682114

Kiparsky M, Bales R. 2017. Advanced data would improve how California manages water. Sacramento Bee. February 9, 2017. www.sacbee.com/ opinion/op-ed/soapbox/article131528914.htm

Kiparsky M, Fisher AT, Hanemann WM, et al. 2018 (in press). Recharge net metering to enhance groundwater sustainability. Issue brief. Center for Law, Energy \& the Environment, UC Berkeley School of Law. Knight R, Smith R, Asch T, et al. In press. Mapping aquifer systems with airborne electromagnetics in the Central Valley of California. Ground Water.
Kocis TN, Dahlke HE. 2017. Availability of high-magnitude streamflow for groundwater banking in the Central Valley, California. Environ Res Lett 12:084009. https://doi. org/10.1088/1748-9326/aa7b1b Marquez MF, Sandoval-Solis S, DeVicentis AJ, et al. 2017. Water budget development for SGMA compliance, case study: Ukiah Valley Groundwater Basin. J Cont Water Res Educ 162:11227. https://doi.org/10.1111/ j.1936-704X.2017.03263.X Méndez-Barrientos LE. (in review). The influence of power asymmetries in institutional development. An empirical view of groundwater institutiona reform in Northern California. (submitted to special issue of Water Alternatives on "Local and national-level politics of groundwater overexploitation")

Nelson R, Perrone D. 2016. Local groundwater withdrawal permitting laws in the south-west US: California in comparative context. Ground Water 54:74753. http://doi.org/10.1111/ gwat.12469

O'Geen AT, Saal M, Dahlke H, et al. 2015. Soil suitability index identifies potential areas for groundwater banking on agricultural lands. Calif Agr 69:7584. https://doi.org/10.3733/ ca.v069n02p75

Perrone D, Jasechko S. 2017. Dry groundwater wells in the western United States. Environ Res Lett 12:104002. https://doi. org/10.1088/1748-9326/aa8ac0
Rudnick J, DeVincentis A, Méndez-Barrientos LE. 2016. The Sustainable Groundwater Management Act challenges the diversity of California farms. Calif Agr 70:169-73. https://do org/10.3733/ca.2016a0015

Zhang Z, Glaser SD, Bales RC, et al. 2017a. Technical report: The design and evaluation of a basin-scale wireless sensor network for mountain hydrology. Water Resour Res 53:4487-98. https://doi. org/10.1002/2016WR019619

Zhang Z, Glaser S, Bales R, et al. 2017b. Insights into mountain precipitation and snowpack from a basin-scale wirelesssensor network. Water Resour Res 53:6626-41. https://doi. org/10.1002/2016WR018825 